\title{
Adenocarcionma Of Mullerian Origin masquerading as an ovarian tumour- a rare case report.
}

\author{
Sarangi $\mathbf{S}^{1}$, Sarkar $\mathbf{U}^{2}$, Chakrabarti $\mathrm{S}^{3}$ \\ ${ }^{1}$ Dr. Sujata Sarangi, ${ }^{2}$ Dr. Urvee Sarkar, ${ }^{3}$ Dr. Suchismita Chakrabarti, All the authors are affiliated with Department Of \\ Pathology, RG Kar Medical College, Kolkata, Address- Department Of Pathology, RG Kar Medical College, 1, \\ Khudiram Bose Road, Kolkata- 700004, India.
}

Address for Correspondence: Dr. Urvee Sarkar, Department of Pathology, RG Kar Medical College, Kolkata. AddressDepartment of Pathology, RG Kar Medical College, 1, Khudiram Bose Road, Kolkata, India. Emaildrurvee.sarkar@gmail.com

\begin{abstract}
Objective: To create awareness about this rare tumour and the way it can mislead the clinician into believing it to be of an ovarian origin. Case report: A 50 years old postmenopausal female presented with a partly solid-partly cystic mass noted arising from the mesentery of sigmoid colon, obliterating the pouch of douglas and adhered to the posterior surface of uterus and right adnexa. The histopathological features were suggestive of Adenocarcinoma of Mullerian origin. Conclusion: Great caution and precision are needed to ascertain the origin and management of these tumours as they carry a bad prognosis.
\end{abstract}

Keywords: Adenocarcinoma, Mullerian, Peritoneal

\section{Introduction}

Adenocarcinoma of Mullerian origin, previously, known as 'mesothelioma of pelvic origin', is a rare primary malignancy of the peritoneum [1]. It is frequently found identical to papillary serous adenocarcinoma of the ovary, hence, also referred to as extraovarian peritoneal serous papillary carcinoma. We present a case of a 50 year old postmenopausal lady presenting with a heterogenous abdominal SOL arising from the mesentery. The mass was diagnosed as Adenocarcinoma of Mullerian origin. It is of value to emphasize that the presentation of the case may be misleading as was in our case where the patient complained of bleeding per vaginum compelling the clinician to suspect carcinoma of the reproductive tract.

\section{Case report}

A 50 years old postmenopausal female came to the Gynaecology and Obstetrics outdoor department with the complaints of bleeding per vaginum. No gross abnormality was noted on physical examination.

CT scan of the abdomen revealed a moderate to large heterogenous solid enhancing mass with irregular necrosis in the right adnexal region pushing the uterus anteriorly, with minimal encysted fluid. Left ovary was found to be bulky and heterogenous in density. No calcification was seen on either side.

On exploratory laparotomy, a partly solid-partly cystic mass was noted arising from the mesentery of sigmoid colon, obliterating the Pouch of Douglas. The mass was adhered to the posterior surface of uterus and right adnexa. The uterus along with the adnexa were grossly normal. Pan-hysterectomy was done along with adhesiolysis and resection of the mass.

Manuscript received: $10^{\text {th }}$ August 2017

Reviewed: $20^{\text {th }}$ August 2017

Author Corrected: $28^{\text {th }}$ August 2017

Accepted for Publication: $4^{\text {th }}$ September 2017 


\section{Case Report}

On gross examination, we found that uterus and cervix measured $6 \times 4 \times 3 \mathrm{~cm}$. Both adnexa were found to be within normal limits. Along with the specimen of TAH-BSO, we found a mass measuring $6 \times 4 \times 2 \mathrm{~cm}$. Cut section showed whitish solid areas with regions of cystic degeneration. Papillary projections were noted on the surface.

Histopathological examination showed a tumour composed of poorly differentiated epithelial cells arranged in sheets and papillary configurations Fig (1).

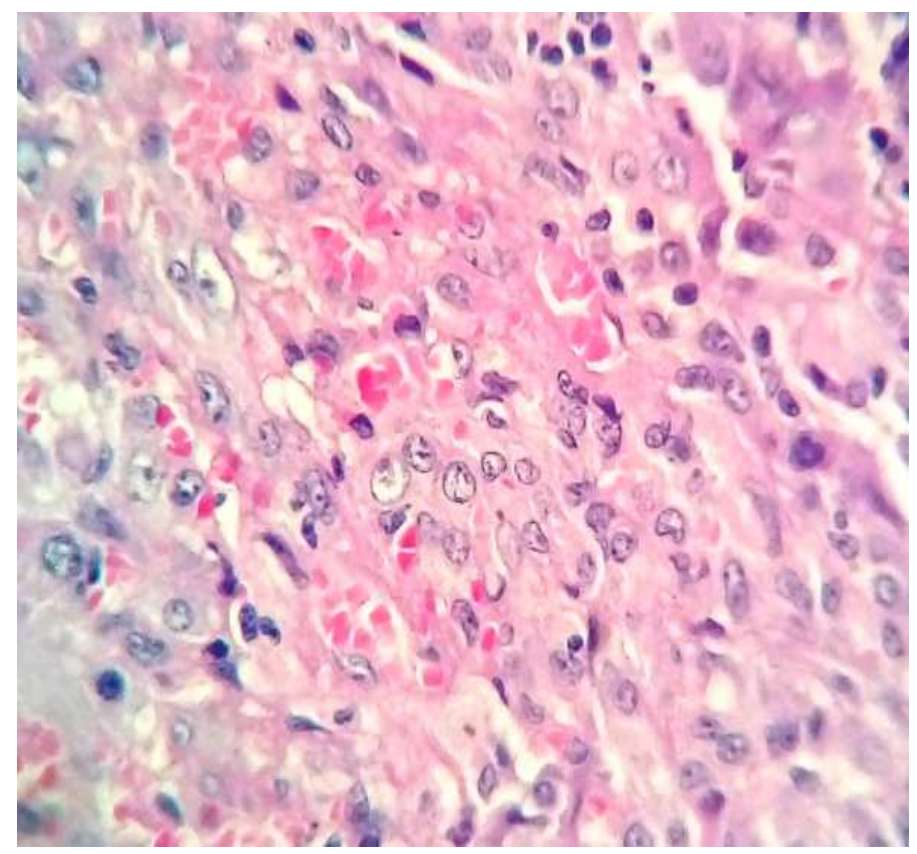

Fig 1: Micrograph showing section from the tumour tissue composed of poorly differentiated epithelial cells arranged in sheets (High power view)

The neoplastic cells were highly anaplastic and bizarre cells with foci of elongated plump spindle cells Fig (2).

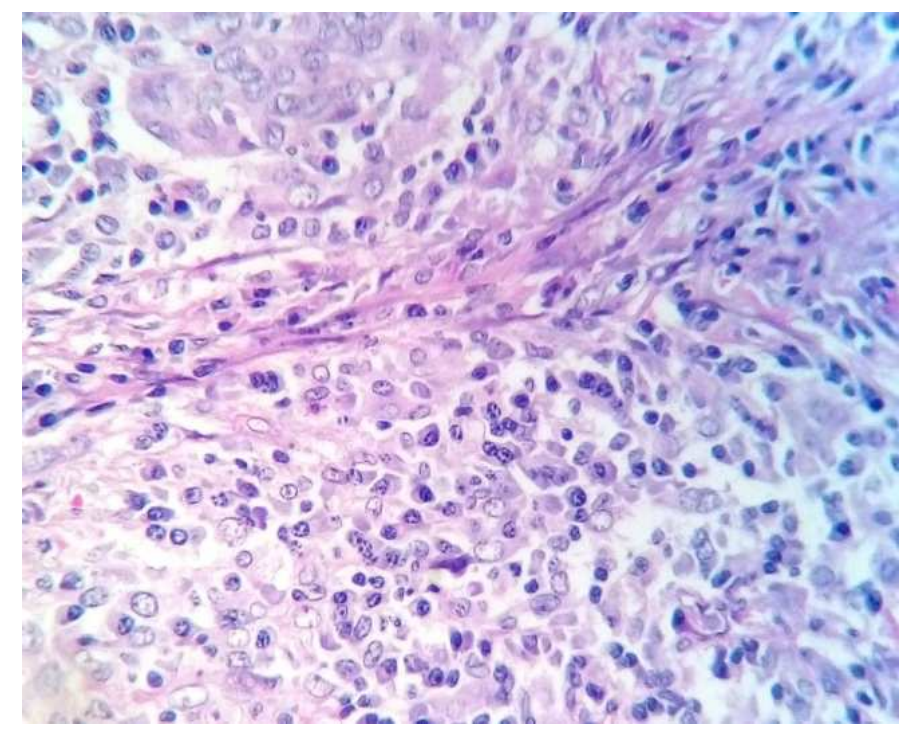

Fig 2: Micrograph of section from the tumour tissue showing highly anaplastic and bizarre cells with foci of elongated plump spindle cells (high power view)

The nuclei were hyperchromatic and irregular and there were many areas of haemorrhage and necrosis. The features were suggestive of Adenocarcarcinoma of Mullerian origin. 


\section{Discussion}

Adenocarcarcinoma of Mullerian origin is a rare fatal entity. Previously this tumour was called Mesothelioma of Pelvic peritoneum resembling papillary serous adenocarcinoma of ovary [1]. This rare malignant tumour is usually seen in 56-62 years of postmenopausal females.

This tumour presents as peritoneal carcinomatosis with no evidence of primary site of origin. The usual presenting features are abdominal pain and ascites. In our case, the patient was a postmenopausal female presenting with bleeding per vaginum [2].

There are various controversies regarding the origin of these tumours; some studies claim them to be of mesothelial origin whereas others have also suggested them to be associated with BRCA1 or p53 mutation and also with pathology of fimbrial end of fallopian tube. [2,3].

In our case the presentation was a bit unusual as the CT scan revealed that the mass arose from the right adnexa, which was disproved only on laparatomy, which showed that both adnexa were normal and the mass was actually located on the posterior aspect of uterus, arising from the mesentery of sigmoid colon.

Adenocarcarcinoma of Mullerian origin can be diagnosed by excluding any primary tumour of ovary and if present, then, the tumour should be confined within the ovarian capsule without any cortical invasion.

This diagnosis is preferred when histology of this tumour resembles that of ovarian serous tumour Various immunohistochemistry panels have been experimented in cases to distinguish this tumour form primary ovarian serous neoplasm. Immunostaining for CK7, WT1, PAX8 and negativity for CK20 is highly indicative of the disease but this panel has not proven to be uniform and of much diagnostic help $[3,4,5,6]$.

According to Patil et al, to prove the tumour to be Adenocarcinoma of Mullerian origin, radiological evidence should also point towards grossly normal uterus and adnexa. Our case was not in concordance with this fact as the innocence of the adnexa was proved on laparotomy and not on radiological study [7].
According to the available research, the prognosis of our tumour is worse than even stage III/IV ovarian carcinoma hence a prompt diagnosis and subsequent treatment is imperative.

Cytoreductive surgery is not the mainstay of treatment. Chemotherapeutic agents like Cisplatin have proved useful [8].

\section{Conclusion}

As these tumours have a worse prognosis than the ovarian carcinomas, they should be treated with great caution and their diagnosis should be accurate as far as possible, so as not to confound the judgement of the medical and radiation oncologist in subsequent management of the case.

Funding: Nil, Conflict of interest: None initiated, Permission from IRB: Yes

\section{References}

1. Swerdlow M. Mesothelioma of the pelvic peritoneum resembling papillary cystadenocarcinoma of the ovary; case report. Am J Obstet Gynecol. 1959;77(1):197-200 doi: $10.4103 / 0973-1075.132653$.

2. Piek JM, van Diest PJ, Zweemer RP, Jansen JW, Poort-Keesom RJ, Menko FH, et al. Dysplastic changes in prophylactically removed Fallopian tubes of women predisposed to developing ovarian cancer. J Pathol. 2001; 195(4): 451-6. doi:10.1002/path.1000.

3. Schorge JO, Muto MG, Lee SJ, Huang LW, Welch WR, Bell DA, Keung EZ, Berkowitz RS, Mok SC. BRCA1- related papillary serous carcinoma of the peritoneum has a unique molecular pathogenesis. Cancer Res. 2000;60:1361-1364.

4. Hou T, Liang D, He J, et al. Primary peritoneal serous carcinoma: a clinicopathological and immunohistochemical study of six cases. Int J Clin Exp Pathol. 2012; 5(8):762-9doi: 10.4103/0973-1075.132653.

5. Phillips V, Kelly P, McCluggage WG. Increased p16 expression in high-grade serous and undifferentiated carcinoma compared with other morphologic types of ovarian carcinoma. Int J Gynecol Pathol. 2009 Mar;28 (2):179-86. doi: 10.1097/PGP.0b013e 318182c2d2. 


\section{Case Report}

6. Cameron RI, Ashe P, O'Rourke DM, Foster H, McCluggage WG. A panel of immunohistochemical stains assists in the distinction between ovarian and renal clear cell carcinoma. Int J Gynecol Pathol. 2003 Jul; 22(3):272-6.

7. Patil RP, Bharambe BM, Mahure AH, Kurdukar MD, Patil AA, Deshpande KA. A case report of primary psammomatous serous adenocarcinoma of the
Peritoneum. S Afr J Obstet Gynaecol 2016; 8(1):1-3. doi. org/10.1080/20742835.2015.1116186.

8. Fowler JM, Nieberg RK, Schooler TA, Berek JS. Peritoneal adenocarcinoma (serous) of Müllerian type: a subgroup of women presenting with peritoneal carcinomatosis. Int J Gynecol Cancer. 1994 Jan; 4 (1): 43-51.

\section{How to cite this article?}

Sarangi S, Sarkar U, Chakrabarti S. Adenocarcionma Of Mullerian Origin masquerading as an ovarian tumour- a rare case report. Trop J Path Micro 2017;3(3):313-316.doi: 10.17511/jopm.2017.i3.15. 